\title{
Dibutyl phthalate promotes juvenile Sertoli cell proliferation by decreasing the levels of the E3 ubiquitin ligase Pellino 2
}

Tan Ma ${ }^{1,2}$, Jiwei Hou ${ }^{1,2}$, Yuan Zhou ${ }^{1,2}$, Yusheng Chen ${ }^{1,2}$, Jiayin Qiu ${ }^{1,2}$, Jiang Wu ${ }^{1,2}$, Jie Ding ${ }^{1,2}$, Xiaodong Han ${ }^{1,2}$ and Dongmei $\mathrm{Li}^{1,2^{*}}$

\begin{abstract}
Background: A previous study showed that dibutyl phthalate (DBP) exposure disrupted the growth of testicular Sertoli cells (SCs). In the present study, we aimed to investigate the potential mechanism by which DBP promotes juvenile SC proliferation in vivo and in vitro.

Methods: Timed pregnant BALB/c mice were exposed to vehicle, or DBP (50, 250, and $500 \mathrm{mg} / \mathrm{kg} / \mathrm{day}$ ) from 12.5 days of gestation until delivery. In vitro, CCK-8 and EdU incorporation assays were performed to determine the effect of monobutyl phthalate (MBP), the active metabolite of DBP, on the proliferation of TM4 cells, which are a juvenile testicular SC cell line. Western blotting analysis, quantitative PCR (q-PCR), and flow cytometry were performed to analyse the expression of genes and proteins related to the proliferation and apoptosis of TM4 cells. Coimmunoprecipitation was used to determine the relationship between the ubiquitination of interleukin 1 receptor-associated kinase 1 (IRAK1) and the effect of MBP on promoting the proliferation of TM4 cells.
\end{abstract}

Results: In the $50 \mathrm{mg} / \mathrm{kg} /$ day DBP-exposed male mice offspring, the number of SCs was significantly increased. Consistent with the in vivo results, in vitro experiments revealed that $0.1 \mathrm{mM}$ MBP treatment promoted the proliferation of TM4 cells. Furthermore, the data showed that $0.1 \mathrm{mM}$ MBP-mediated downregulation of the E3 ubiquitin ligase Pellino 2 (Peli2) increased ubiquitination of IRAK1 by K63, which activated MAPK/JNK signalling, leading to the proliferation of TM4 cells.

Conclusions: Prenatal exposure to DBP led to abnormal proliferation of SCs in prepubertal mice by affecting ubiquitination of the key proliferation-related protein IRAK1 via downregulation of Peli2.

Keywords: Dibutyl phthalate, Monobutyl phthalate, Sertoli cells, Apoptosis, Peli2, Proliferation

\footnotetext{
* Correspondence: lidm@nju.edu.cn

'Immunology and Reproduction Biology Laboratory \& State Key Laboratory of Analytical Chemistry for Life Science, Medical School, Nanjing University, Nanjing 210093, Jiangsu, China

${ }^{2}$ Jiangsu Key Laboratory of Molecular Medicine, Nanjing University, Nanjing 210093, Jiangsu, China
}

C C The Author(s). 2020 Open Access This article is licensed under a Creative Commons Attribution 4.0 International License, which permits use, sharing, adaptation, distribution and reproduction in any medium or format, as long as you give appropriate credit to the original author(s) and the source, provide a link to the Creative Commons licence, and indicate if changes were made. The images or other third party material in this article are included in the article's Creative Commons licence, unless indicated otherwise in a credit line to the material. If material is not included in the article's Creative Commons licence and your intended use is not permitted by statutory regulation or exceeds the permitted use, you will need to obtain permission directly from the copyright holder. To view a copy of this licence, visit http://creativecommons.org/licenses/by/4.0/. The Creative Commons Public Domain Dedication waiver (http://creativecommons.org/publicdomain/zero/1.0/) applies to the data made available in this article, unless otherwise stated in a credit line to the data. 


\section{Background}

Dibutyl phthalate (DBP) is a widely used plasticizer that has a negative effect on the development and function of male reproductive organs in humans and laboratory animals $[1,2]$. As DBP binds to the matrix by non-covalent bond, it easily leaches into the environment and then migrates into the food [2]. The toxicological effects of DBP are complex and diverse. Among them, the impact of in utero exposure to DBP on foetal reproduction and development is particularly worthy of concern. Some studies confirmed that in utero exposure to DBP caused testicular malformations in male offspring [3-5], but the underlying mechanism has not yet fully investigated. As one of the target cells of DBP/MBP [5-9], Sertoli cells (SCs) are the first that are recognized to differentiate in the foetal indifferent gonad, and they play a critical role in foetal testis formation and sexual differentiation as well as in adult spermatogenesis [10-12]. Because of the fixed number of germ cells supported by SCs, the proliferative capability of immature SCs during prepuberty determines the number of mature SCs, testis size and output of germ cells in the mature testis. Our recent study suggested that monobutyl phthalate (MBP), the metabolite of DBP, could disrupt the growth of juvenile SCs [9], however, the underlying molecular mechanism still needs to be further explored.

Based on the data generated by screening a highthroughput mRNA microarray, downregulation of E3 ubiquitin ligase Pellino 2 (Peli2) was found in SCs after exposure to $0.1 \mathrm{mM}$ MBP [9]. Peli2, a member of the Pellino protein family, is a novel E3-RING ubiquitin ligase involved in the ubiquitination and degradation of interleukin-1 receptor-related kinase 1 (IRAK1). Previous studies revealed that Peli2 mediated K63-linked IRAK1 polyubiquitination and reduced K48-linked IRAK1 polyubiquitination, thereby leading to the activation of downstream MAPK/JNK signalling pathways [13-15]. The activation of IRAK1 downstream of the MAPK/JNK signalling pathway is related to many cellular processes, such as cell proliferation, migration, and regeneration [16, 17]. Meanwhile, both the extrinsic apoptotic pathway involving the Fas/FasL proteins, such as FADD, and the intrinsic pathway (mitochondria-mediated through the $\mathrm{Bax} / \mathrm{Bcl}-2$ family proteins) can regulate cell growth by inducing the apoptosis of SCs [18]. Given these previous studies, we raised the question of whether the Peli2-mediated proliferation pathway as well as apoptotic pathways were involved in MBP-mediated growth disruption of immature SCs.

In this study, we first evaluated the effect of DBP/ MBP on proliferation and apoptosis in vivo and in vitro, and then we investigated the molecular mechanism by which MBP promotes the proliferation of TM4 cells.

\section{Methods}

\section{Animals and processing method}

Nine-week-old male $(n=12)$ and female $(n=24)$ specific pathogen-free (SPF) BALB/c mice were obtained from the Experimental Animal Center of the Academy of Military Medical Science, Beijing, China. Time-mated females (day of vaginal plug = gestational day (GD) 0.5$)$ were randomized into 4 groups $(n=6$ for each group). Pregnant mice were treated with 0 (control), 50, 250, or $500 \mathrm{mg} / \mathrm{kg} /$ day DBP (Sigma, St. Louis, USA) in $1 \mathrm{ml} / \mathrm{kg}$ corn oil, which was administered daily by oral gavage from GD 12.5 until birth. Because seminiferous cord and gonocyte development of offspring were damaged under the daily oral dose of $500 \mathrm{mg} / \mathrm{kg} /$ day DBP given to pregnant mice from GD 16-18 [19], we set $500 \mathrm{mg} / \mathrm{kg} /$ day as the highest concentration group. The 22-day-old males were euthanized by $\mathrm{CO}_{2}$ asphyxiation. The testes were carefully removed and fixed in $4 \%$ paraformaldehyde.

All procedures performed on animals were approved by the Animal Care and Use Committee of Nanjing University under the animal protocol number SYXK $\mathrm{Su}$ ) 2009-0017. The animal experiments were performed in accordance with the Guide for the Care and Use of Laboratory Animals (The Ministry of Science and Technology of China, 2006).

\section{Reagents and cell culture}

Foetal bovine serum (FBS), Triton ${ }^{\circ} \mathrm{X}-100$, DMEM-F12 and MBP were purchased from Sigma-Aldrich Inc. (St. Louis, MO, USA). MBP (2.2224 g) was dissolved in $1 \mathrm{~mL}$ of DMSO to prepare a stock solution (10 M). SP600125 (JNK inhibitor) and an IRAK1 inhibitor were purchased from MedChemExpress (Monmouth Junction, NJ, USA). The antibodies used in this study are listed in Additional file 1: Table S1. TM4 cells were cultured in DMEM/F12 containing 10\% FBS and 1\% penicillinstreptomycin with a $5 \% \mathrm{CO}_{2}$ atmosphere in a humidified incubator at $37^{\circ} \mathrm{C}$. TM4 cell lines were obtained from the American Type Culture Collection (Manassas, VA, USA).

\section{Immunohistochemical analyses}

Immunohistochemical analyses were carried out as previously described [20]. The primary and secondary antibodies used in this study were SOX9, Peli2, and HRP-conjugated secondary antibodies (Zhongshan Biotechnology, Beijing, China). For each section, ten images were randomly captured at 200x magnification under a light microscope. The total cells and the SOX9- or Peli2-positive cells in each image were counted automatically using Image software. After calculating the average of ten images, excluding the minimum and maximum values, the positive ratio of 
SOX9- or Peli2-expressing cells was determined; six sections per group of mice were taken for statistical analysis.

\section{Cell growth assay}

A Cell Counting Kit-8 (CCK-8) (Dojindo Lab., Kumamoto, Japan) test was used to test cell growth after treatment with MBP according to the manufacturer's instructions. Briefly, TM4 cells were plated at $2 \times 10^{3}$ cells per well in 96-well culture plates. After $24 \mathrm{~h}$, cells were treated with MBP at concentrations of 0 , $0.1,1$ or $10 \mathrm{mM}$ for various times $(1,2,3,4$, or 5 days). Based on our previous study of cell viability, the median effective concentration $\left(\mathrm{EC}_{50}\right)$ of $\mathrm{MBP}$ was determined to be $16.21 \mathrm{mM}$ [21]. In this study, the highest concentration of MBP used was $10 \mathrm{mM}$. Following MBP treatment, $100 \mu \mathrm{L}$ of a mixed solution of $1: 10(\mathrm{v} / \mathrm{v})$ CCK-8:DMEM/F12 was added to each well, and the cells were incubated for an additional 4 h. Absorbance was measured at the indicated time points at $450 \mathrm{~nm}$ with a microplate reader (Versamax, Chester, PA, USA). CCK-8 contains WST-8, which can be reduced by dehydrogenases in cells to generate an orange-coloured product (formazan), which is soluble in the tissue culture medium. Therefore, the amount of formazan dye generated by dehydrogenases in cells is directly proportional to the number of living cells. Measurements were performed at least three times on six samples in parallel. Cell survival rate $=(\mathrm{As}-\mathrm{Ab}) /(\mathrm{Ac}-\mathrm{Ab}) * 100 \%$, and the terms are defined as follows: As: experiment well; Ab: blank well; and Ac: control well.

\section{EdU incorporation assay}

EdU assay kits were used to determine cell proliferation (Click-iT ${ }^{\oplus}$ EdU Imaging Kits; Invitrogen). According to the kit's instructions, $1 \mathrm{~mL}$ of proliferation media containing $20 \mu \mathrm{M}$ EdU (final concentration $10 \mu \mathrm{M})$ was added to 6 wells of the plate, containing cells to be incubated with final concentrations of 0 , $0.1,1$ or $10 \mathrm{mM}$ MBP for $24 \mathrm{~h}$. Cells were then fixed with $4 \%$ paraformaldehyde for $15 \mathrm{~min}$. The fixative was removed, and the cells were washed twice with 1 $\mathrm{mL}$ of $3 \%$ bovine serum albumin (BSA), which was followed by incubation with $0.5 \%$ Triton X-100 (Sigma-Aldrich, St. Louis, MO,USA) for $10 \mathrm{~min}$ at room temperature. The cells were then washed twice and incubated with $1 \mathrm{~mL}$ of Click-iT ${ }^{\circ}$ reaction cocktail for $30 \mathrm{~min}$ at room temperature. The cells were then incubated with $100 \mu \mathrm{L}$ of $5 \mu \mathrm{g} / \mathrm{mL}$ DAPI (Sigma-Aldrich) for an additional $30 \mathrm{~min}$ in the dark. After staining, the cells were captured at $600 \times$ magnification under a microscope (Olympus, Tokyo, Japan). DAPI is a nuclear stain used to determine total cell counts. Normally, DAPI bound to DNA is most strongly excited by ultraviolet (UV) light at $358 \mathrm{~nm}$ and produces the strongest emission in the blue range at $461 \mathrm{~nm}$. Six fields for each sample were randomly captured. EdU-positive cells were counted using ImageJ software (NIH, Bethesda, MD).

\section{Flow cytometry for apoptosis assay}

TM4 cell apoptosis after treatment with different MBPs was analysed using Annexin V-FITC and PI staining kits (Vazyme, Nanjing, China) according to the manufacturer's requirements. Flow cytometry was performed on a FACSCalibur flow cytometer (BD Biosciences), and the data were analysed using Paint-A-Gate software (Becton-Dickson, San Jose, CA).

\section{Quantitative PCR (q-PCR) validation analyses of target genes}

Analyses of q-PCR were performed as previously described [20]. Total RNA was extracted using TRIzol reagent (Invitrogen, Carlsbad, CA) according to the manufacturer's protocol. HiScript Q RT SuperMix for q-PCR kit (Vazyme, Nanjing, China) was used for reverse transcription polymerase chain reactions, and then q-PCR assays were conducted with SYBR Green I mix (Takara, Dalian, China) on an ABI ViiA 7 Q-PCR System (Applied Biosystems, Waltham, MA). In all cases, mRNA levels were normalized to the expression of GAPDH, which served as an endogenous control. The relative expression of target genes was calculated by the $2^{-\Delta \Delta \mathrm{Ct}}$ method [22]. The primer sets used in this study are listed in Additional file 1: Table S2.

\section{Western blotting, coimmunoprecipitation (Co-IP)}

Western blotting analyses were executed as previously described [23]. Specific antibody immunological complexes such as Peli2, IRAK1, Bax, Bcl-2, FADD, cl-Caspase 8, cl-Caspase 3, cyclin dependent kinase 1 (CDK1), Caspase 3, p-JNK, JNK, c-Jun, p-c-Jun and GAPDH, were observed by enhanced chemiluminescence. To detect the ubiquitination of IRAK1, an anti-IRAK1 antibody was used to first isolate IRAK1 from TM4 cells by immunoprecipitation, and then ubiquitination of IRAK1 was analysed by immunoblotting using an antibody against ubiquitination (Ub) or K63-Ub.

\section{Statistical analyses}

SPSS 18.0 (SPSS, Chicago, IL) was used for statistical analysis. The normality and homogeneity of variances in the data were checked by using Levene's test. The Student's t-test was used for paired comparisons. To 
compare more than two groups, we used one-way ANOVA with Duncan's post hoc test. $P<0.05$ was considered statistically significant.

\section{Results}

The effect of DBP on the proliferation of SCs

Following in utero exposure to $50 \mathrm{mg} / \mathrm{kg} /$ day DBP, the number of SOX9 (a marker of SCs)-positive cells in the testes of pups from the resulting male offspring at postnatal day (PND) 22 was significantly increased compared with the vehicle treatment group; SOX9 was detected by immunohistochemical assay (Fig. 1a, b). These in vivo results suggested that DBP stimulated the proliferation of SCs at a dose of $50 \mathrm{mg} / \mathrm{kg} /$ day.

The effect of MBP on TM4 cell growth and DNA synthesis The results showed that $0.1 \mathrm{mM}$ MBP promoted cell proliferation, but $10 \mathrm{mM} \mathrm{MBP}$ inhibited the proliferation of TM4 cells (Fig. 2a). Compared with no treatment, 0.1 $\mathrm{mM}$ MBP increased the number of EdU-positive cells, indicating that $0.1 \mathrm{mM}$ MBP promoted DNA synthesis in TM4 cells (Fig. 2b, c). Collectively, these in vitro data

(a)
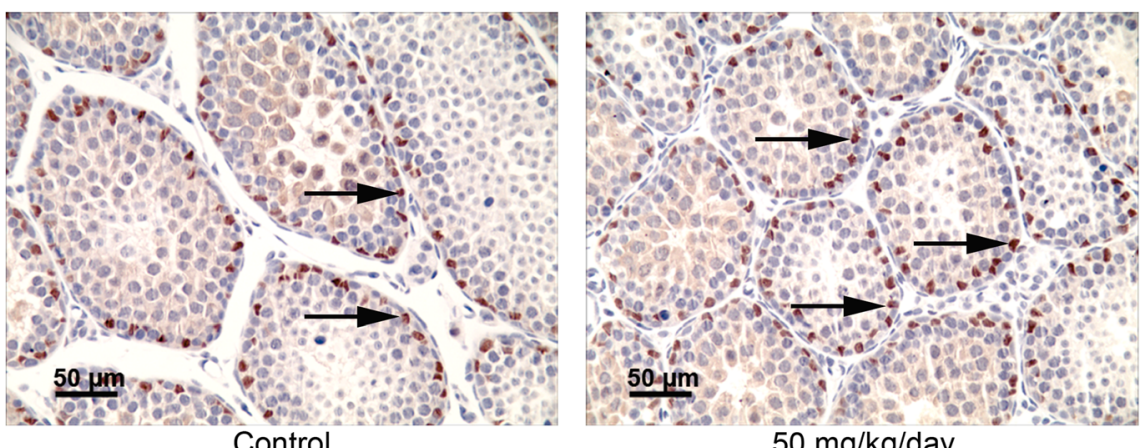

Contro
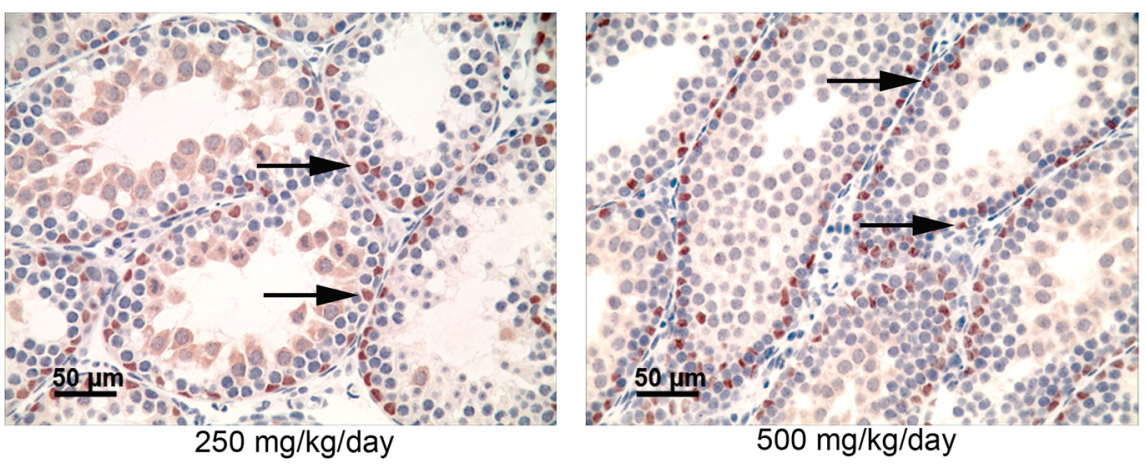

(b)

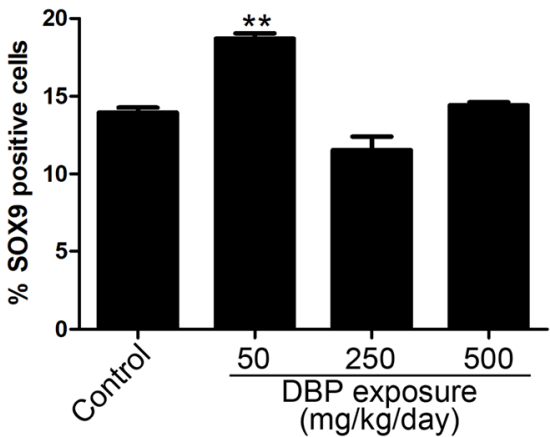

Fig. 1 The effect of dibutyl phthalate (DBP) on Sertoli cell (SC) proliferation. a The effect of DBP on the number of Sertoli cells per testis in mice after prenatal exposure to DBP. Testicular sections were collected from pups 22 days after mice were exposed in utero (GD12.5 - birth) to corn oil or DBP doses of 50, 250 or $500 \mathrm{mg} / \mathrm{kg} /$ day. Immunohistochemical staining for SOX9 was performed (scale bar $50 \mu \mathrm{m}$ ). Arrows represent the expression of SOX9 in the testes of DBP-treated and control male pups. b The ratio of SOX9-positive cell was detected by ImageJ $(n=6)$. The results are expressed as the means \pm SEM. ${ }^{*} p<0.05 ;{ }^{* *} p<0.01$, compared with control 
(a)

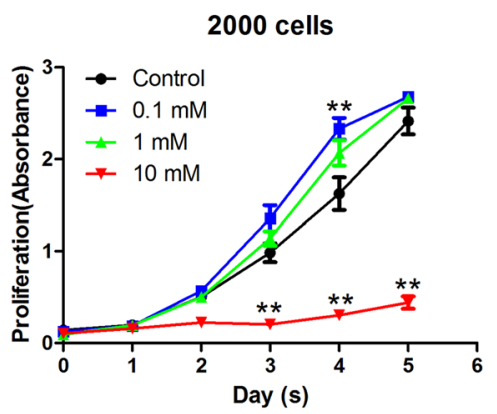

(b)

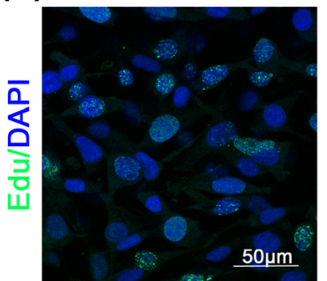

Control

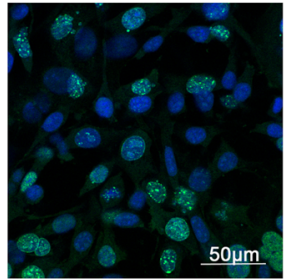

0.1 (c)
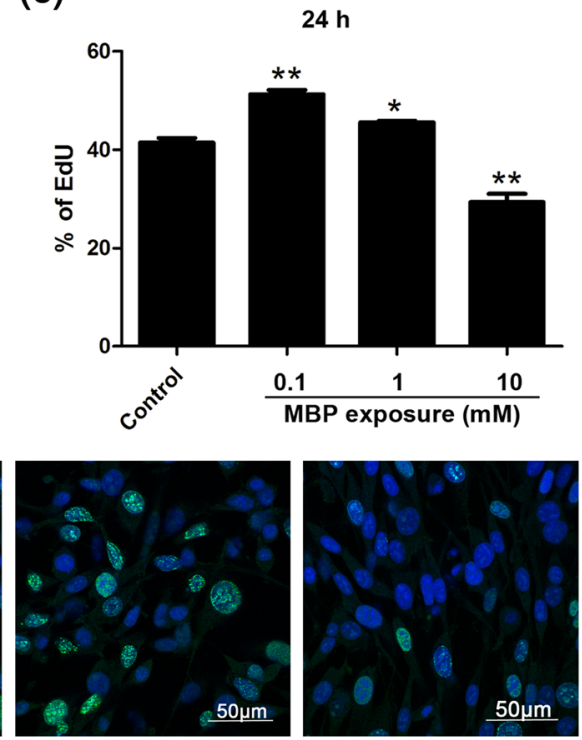

1

MBP exposure (mM)

Fig. 2 The effect of monobutyl phthalate (MBP) on the proliferation of TM4 cells. a Cell viability was measured by CCK-8 assay and showed the viability of TM4 cells after treatment with different concentrations of MBP for 5 days $(n=3)$. b Immunofluorescence staining showed EdU incorporation in TM4 cells without treatment (control) or following treatment with $0.1,1$, or $10 \mathrm{mM}$ for $24 \mathrm{~h}$. DAPI was used to counterstain cell nuclei. c Quantification of the average percentage of EdU+ cells for B $(n=6)$. The results are expressed as the means \pm SEM. ${ }^{*} p<0.05$; ** $p<0.01$, compared with control

confirmed that $0.1 \mathrm{mM}$ MBP stimulated the proliferation of TM4 cells.

The effect of MBP on the apoptosis of TM4 cells

The results of flow cytometry showed that the apoptosis rates of TM4 cells were significantly increased in the $1 \mathrm{mM}$ and $10 \mathrm{mM}$ MBP treatment groups (Fig. 3a, b). To elucidate the mechanism by which MBP induced apoptosis, we examined the effects of MBP on Bcl-2 and Bax expression as well as cytochrome c (Cyt c) release, which are indicators of the intrinsic apoptotic pathways. The Bax/Bcl-2 ratio, as an apoptotic index, is used to evaluate the balance between apoptotic and anti-apoptotic proteins. The results showed that the Bax/Bcl-2 ratio was markedly decreased after exposure to $0.1 \mathrm{mM}$ MBP (Fig. 3c). However, the $\mathrm{Bax} / \mathrm{Bcl}-2$ ratio increased in the $10 \mathrm{mM}$ MBP group. Furthermore, the release of Cyt $\mathrm{c}$ into the cytosol was significantly increased in TM4 cells after exposure to $10 \mathrm{mM}$ MBP (Fig. 3d, Additional file 1: Fig. S1). We also detected the activation of the extrinsic apoptotic pathway in TM4 cells and found that the extrinsic apoptosis pathway was inhibited after exposure to $10 \mathrm{mM}$ MBP (Additional file 1: Fig. S2). These data indicated that exposure to $10 \mathrm{mM}$ MBP induced apoptosis of TM4 cells by activating the intrinsic apoptotic pathway.

\section{The effect of DBP/MBP on Peli2 expression}

Based on microarray data in the GEO (Gene Expression Omnibus) database from our previous report [9], Peli2 was chosen for further study because of its important role in cell proliferation. We demonstrated that prenatal exposure to DBP $(50 \mathrm{mg} / \mathrm{kg} /$ day) reduced the levels of Peli2 in the mouse testes, as shown by immunohistochemical staining (Fig. 4a, b). Moreover, the qPCR results showed that Peli2 expression in the 0.1 $\mathrm{mM}$ MBP group was significantly lower than it was in the control, whereas it was increased in the $10 \mathrm{mM}$ group (Fig. 4c), which was further confirmed by Western blotting (Fig. 4d, e).

\section{The effect of MBP on the ubiquitination of IRAK1 in TM4} cells

Peli2 protein, a RING E3-ubiquitin ligase, can lead to the degradation of IRAK1 by promoting IRAK1 ubiquitination $[24,25]$, which eventually inhibits the activation of the downstream MAPK/JNK signalling pathway [26]. In this study, we found that the mRNA level of IRAK1 was significantly increased at $0.1 \mathrm{mM} \mathrm{MBP}$, whereas it was suppressed at $10 \mathrm{mM}$ (Fig. 5a). Western blotting results also showed that the protein level of IRAK1 was increased after exposure to $0.1 \mathrm{mM}$ MBP (Fig. 5b, c). A previous study showed that Peli2 played a key role in IL- 


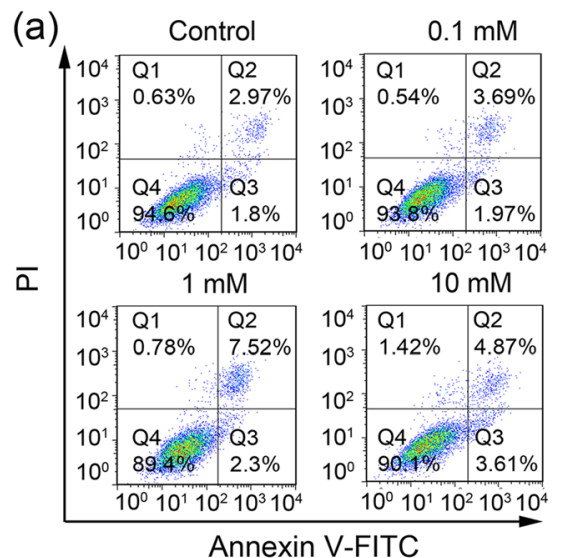

(c)
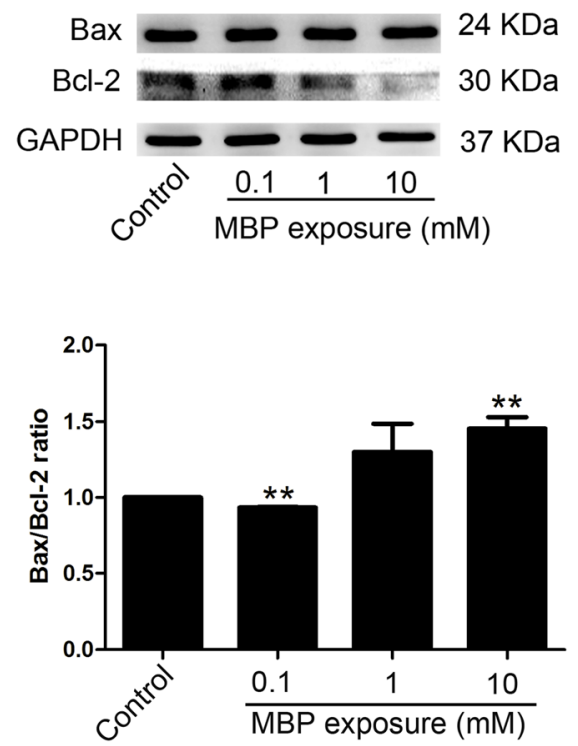

(b)

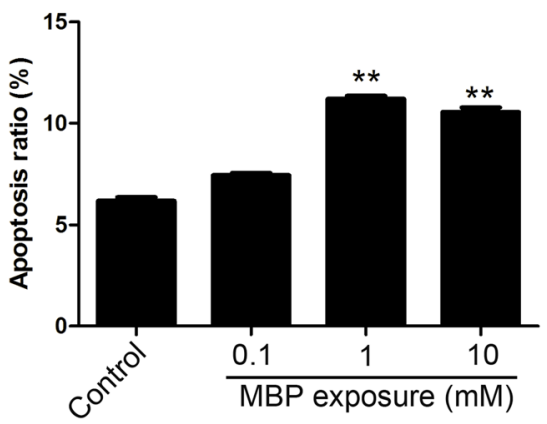

(d)
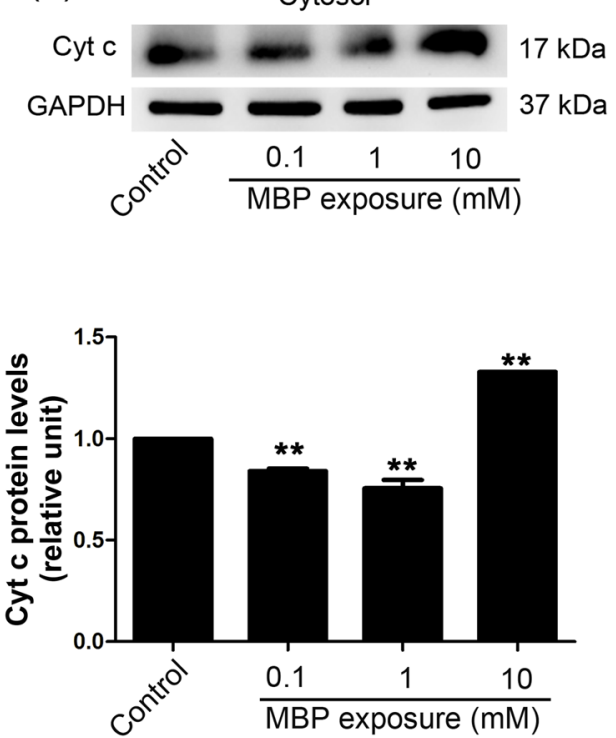

Fig. 3 The intrinsic apoptotic pathway participated in MBP-induced apoptosis of TM4 cells. a Annexin V-FITC/PI was used to stain apoptotic cells, which were analysed by flow cytometry at $24 \mathrm{~h}$. $\mathbf{b}$ The level of apoptosis in TM4 cells was calculated $(n=3)$. $\mathbf{c}$ The protein levels of Bax and Bcl-2 in TM4 cells treated with different concentrations of MBP were measured by Western blotting; the Bax/BCl-2 ratio was determined by ImageJ (lower panels, $n=3$ ). GAPDH was assessed as an internal control. $\mathbf{d}$ Cytochrome c (Cyt c) release was detected in the cytosolic (Cytosol) fraction of MBP treated TM4 cells $24 \mathrm{~h}$ by Western blotting. The densitometry data were quantified with ImageJ (lower panels, $n=3$ ). GAPDH was assessed as an internal control. The results are expressed as the means \pm SEM. ${ }^{* *} p<0.01 ;{ }^{*} p<0.05$

1- and LPS-induced K63- and K48-linked IRAK1 ubiquitination [27]; thus, we explored IRAK1 ubiquitination by Co-IP. The results showed that after exposure to 0.1 $\mathrm{mM}$ MBP, total polyubiquitination of IRAK1 was attenuated compared with that in control cells, while K63mediated polyubiquitination of IRAK1 was increased (Fig. 5d). To determine whether IRAK1 was upstream of MAPK/JNK, we examined the effects of an IRAK1 inhibitor on MAPK/JNK activation. The IRAK1 inhibitor reduced p-JNK expression at the protein level (Fig. 5e, f). These data suggested that K63-mediated polyubiquitination of IRAK1 might play a key role in DBP/MBP-mediated proliferation of TM4 cells.

\section{MBP promoted TM4 cell proliferation by MAPK/JNK signalling}

We detected the activation of the MAPK/JNK signalling pathway by assessing downstream members of the pathway by Western blotting. The results showed that the phosphorylation of both JNK (p-JNK) and c-Jun (p-cJun) was significantly increased in TM4 cells treated with $0.1 \mathrm{mM}$ MBP (Additional file 1: Fig. S3a, S3b). Additionally, the phosphorylation of c-Jun in the testis after in utero exposure to $50 \mathrm{mg} / \mathrm{kg} /$ day DBP was significantly increased (Additional file 1: Fig. S3c, S3d). Furthermore, $0.1 \mathrm{mM}$ MBP also induced marked enrichment of c-Jun in the nuclei of TM4 cells (Fig. 6a, b). To identify 
(a)

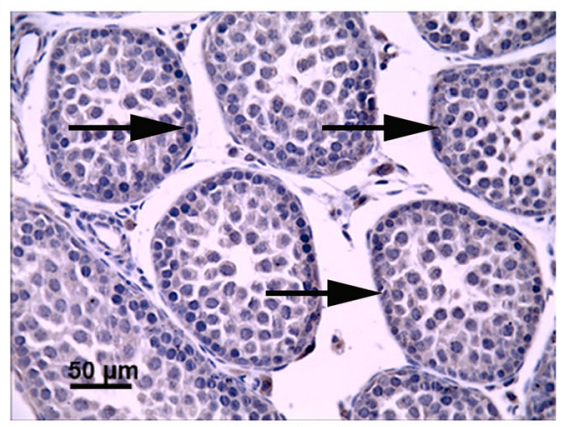

Control

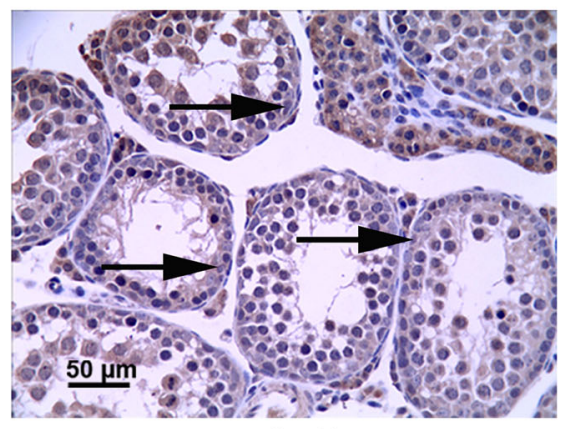

(b)

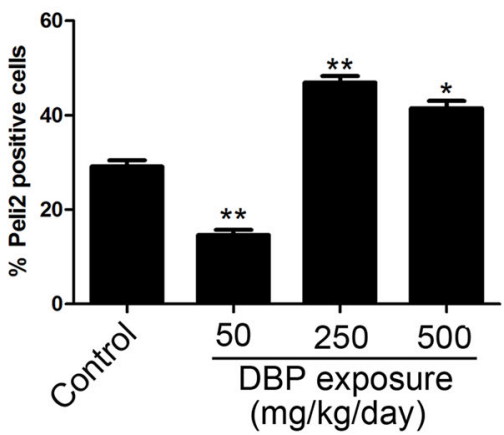

(d)

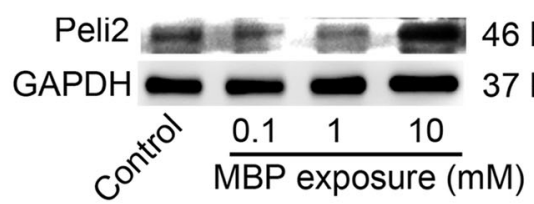

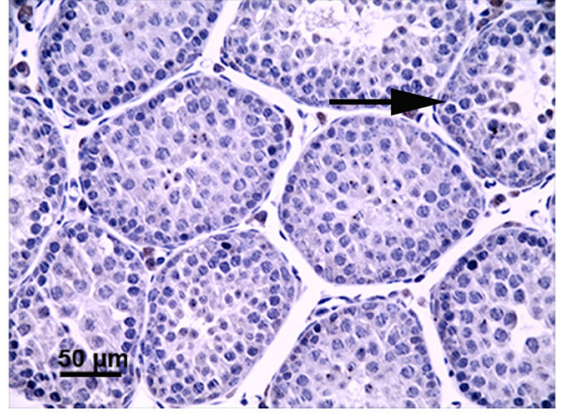

$50 \mathrm{mg} / \mathrm{kg} /$ day

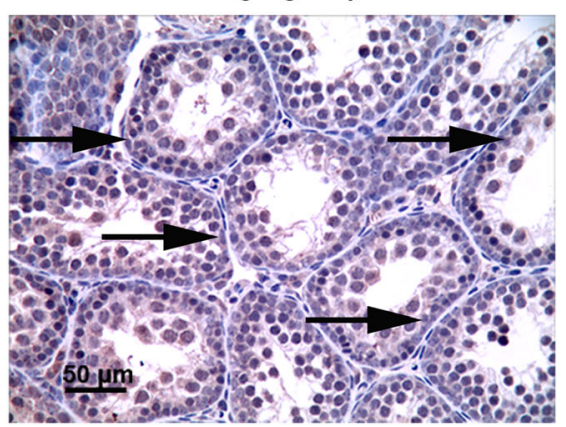

$500 \mathrm{mg} / \mathrm{kg} / \mathrm{day}$

(c)

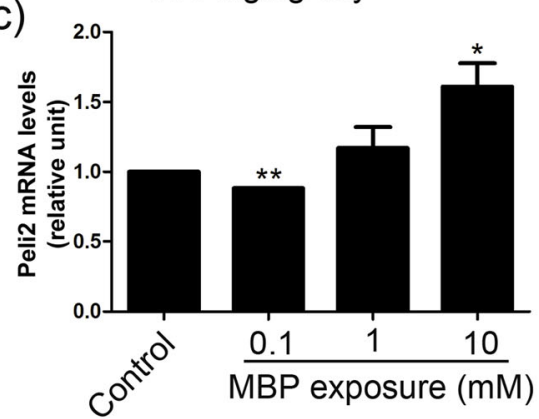

(e)

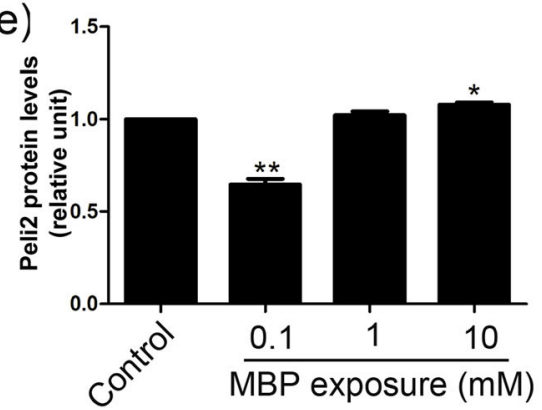

Fig. 4 The effects of DBP/MBP exposure on Peli2 expression. $\mathbf{a}$, $\mathbf{b}$ Testicular sections were collected from pups 22 days after they were exposed in utero (GD12.5 - birth) to corn oil or DBP doses of 50,250 or $500 \mathrm{mg} / \mathrm{kg} /$ day. The expression of Peli2 in mouse testicular tissues was carried out by immunohistochemistry. Arrows represent the expression of Peli2 in the testes of DBP-treated and control male pups. The ratio of positive cells was detected by ImageJ $(n=6)$. The expression of Peli2 in SCs after exposure to different concentrations of MBP for $24 \mathrm{~h}$. c The mRNA levels of Peli2 were measured with quantitative PCR (q-PCR), and GAPDH was measured as a loading control. $\mathbf{d}$, e Peli2 protein levels were measured by Western blotting. The densitometry data were quantified with ImageJ $(n=3)$. GAPDH was assessed as an internal control. The results are expressed as the means \pm SEM. ${ }^{* *} p<0.01 ;{ }^{*} p<0.05$ 
(a)

(b)

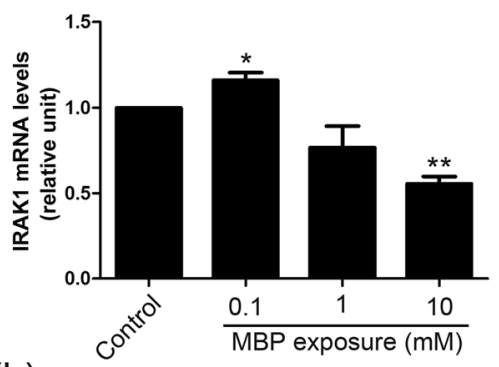

(c)
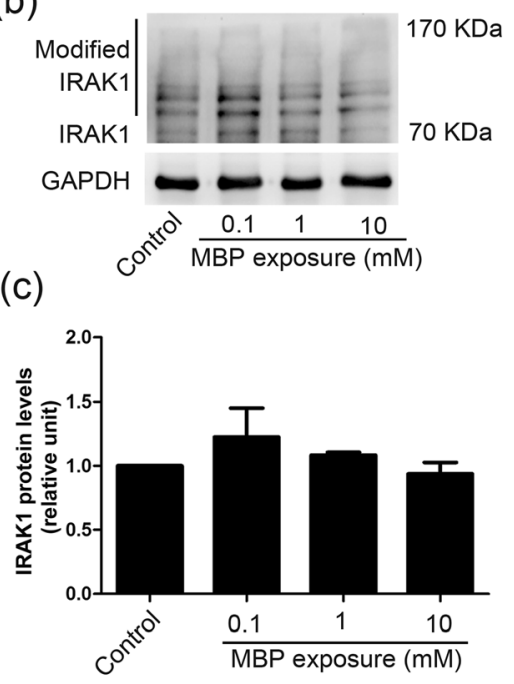

(e)

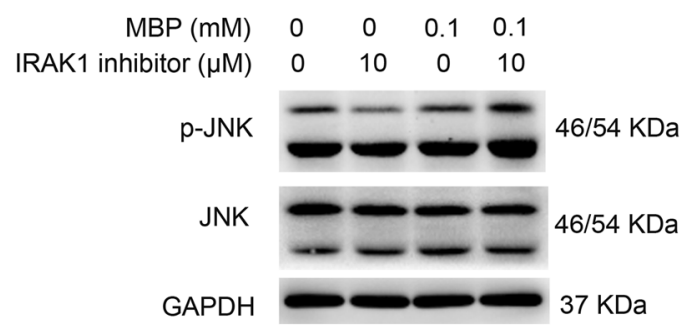

(d)

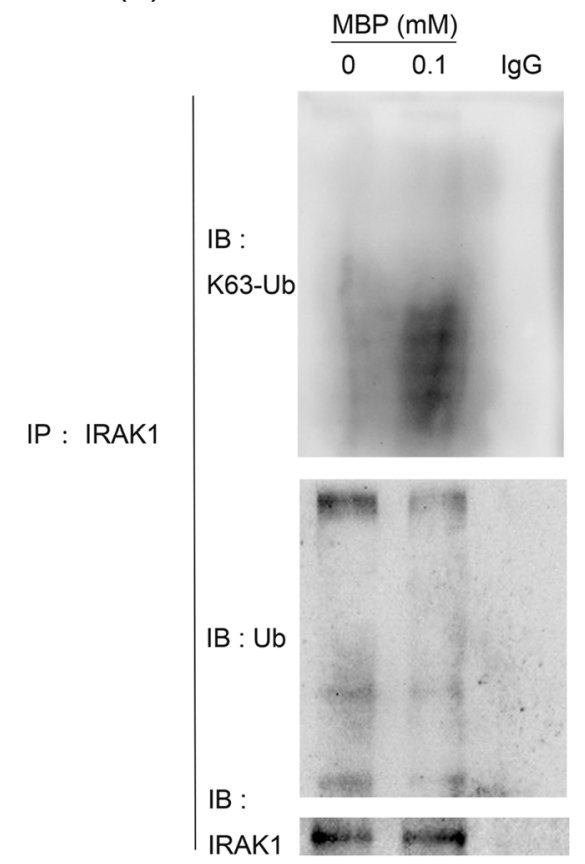

(f)

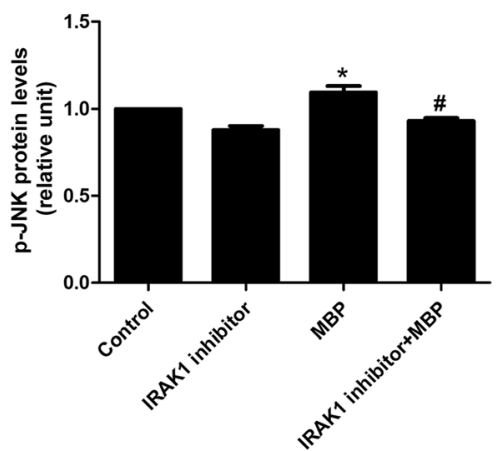

Fig. 5 The ubiquitination of IRAK1 in TM4 cells after exposure to MBP. (a-c) The expression of IRAK1 in TM4 cells after exposure to different concentrations of MBP for $24 \mathrm{~h}$. a The mRNA levels of IRAK1 were measured with $\mathrm{q}-\mathrm{PCR}$, and GAPDH was measured as a loading control. $\mathbf{b}$, $\mathbf{c}$ The protein levels of IRAK1 were measured by Western blotting. The densitometry data were quantified with ImageJ $(n=3)$. GAPDH was assessed as an internal control. d MBP $(0.1 \mathrm{mM})$ attenuates IRAK1 ubiquitination and stimulates K63-mediated IRAK1 polyubiquitination. Cell lysates were immunoprecipitated (IP) with anti-IRAK1, which was followed by Western blotting analysis with anti-K63 ubiquitin (K63-Ub), anti-ubiquitin (Ub), and anti-IRAK1 antibodies. e, f TM4 cells were pretreated with an IRAK1 inhibitor for $1 \mathrm{~h}$, which was followed by $24 \mathrm{~h}$ treatment with $0.1 \mathrm{mM}$ MBP. The expression levels of JNK and p-JNK were determined by Western blotting. The densitometry data were quantified with ImageJ $(n=3)$. GAPDH was assessed as an internal control. The results are expressed as the means \pm SEM. ${ }^{* *} p<0.01$; ${ }^{*} p<0.05$. \# $p<0.05$, vs MBP exposure

whether MAPK/JNK was responsible for the proliferation of TM4 cells, we examined the effects of the JNK inhibitor SP600125 on cell proliferation. The activation of the MAPK/JNK pathway was inhibited after pretreatment with the JNK inhibitor SP600125 (Fig. 6c, d). Furthermore, the MBP-induced increased expression of CDK1 was reduced after pretreatment with the JNK inhibitor SP600125, suggesting that MAPK/JNK participated in MBP-induced TM4 cell proliferation. These results were further confirmed by flow cytometry (Fig. 6e, f). 
(a)

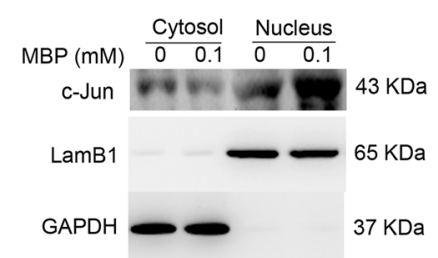

(c)

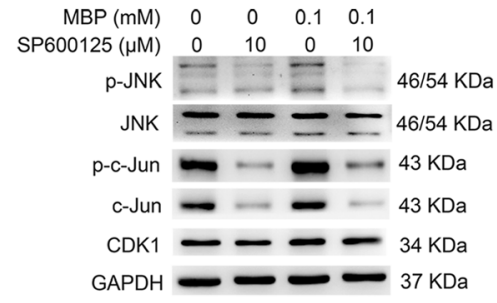

(e)

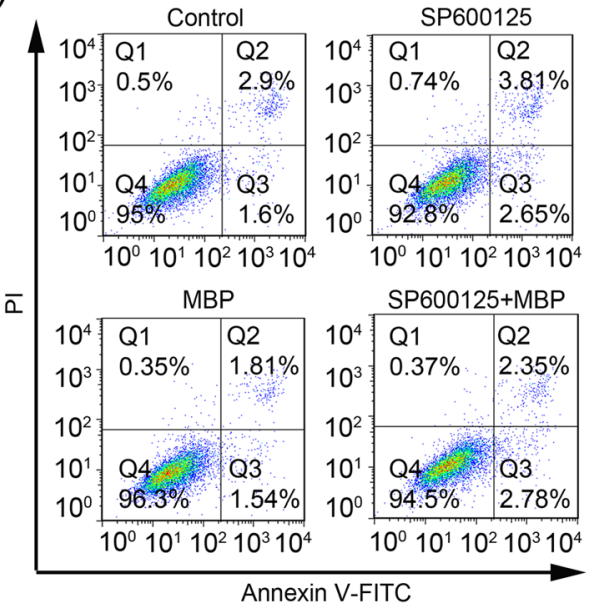

(b)

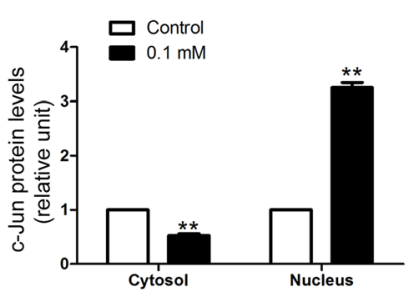

(d)

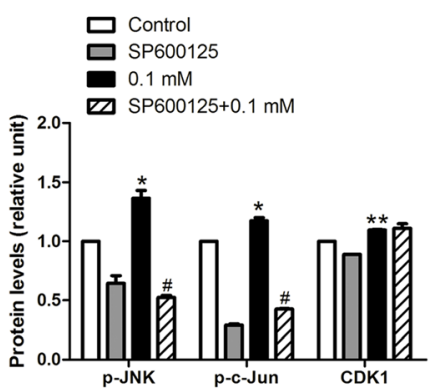

(f)

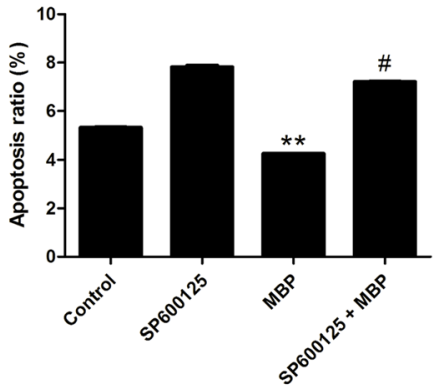

Fig. 6 MAPK/JNK signalling is responsible for the proliferation of TM4 cells stimulated by $0.1 \mathrm{mM} \mathrm{MBP.} \mathbf{a}, \mathbf{b}$ Nuclear and cytosolic fractions were prepared from control and MBP-induced TM4 cells. Levels of c-Jun were analysed by Western blotting. GAPDH and Lamin B1 served as cytosolic and nuclear markers, respectively. The expression levels of c-Jun in the nucleus and cytosol were quantified with ImageJ (right panel; $n=3$ ). $\mathbf{c}$, $\mathbf{d}$ TM4 cells were pretreated with SP600125 for $1 \mathrm{~h}$, which was followed by $24 \mathrm{~h}$ of treatment with $0.1 \mathrm{mM} \mathrm{MBP}$. (c) Expression levels of c-Jun, p-cJun, JNK, p-JNK and cyclin dependent kinase 1 (CDK1) were determined by Western blotting. (d) The densitometry data were quantified with ImageJ $(n=3)$. GAPDH was run as an internal control. e, f Apoptotic cells were determined by flow cytometry. The level of apoptosis in TM4 cells was calculated $(n=3)$. The data are expressed as the means \pm SEM. ${ }^{* *} p<0.01 ;{ }^{*} p<0.05$, vs control. \# $p<0.05$, vs MBP exposure

\section{Discussion}

As an endocrine disruptor found in the environment, DBP is of concern because it is currently widely used in many products, including latex adhesives, cellulose acetate plastics, dyes, personal care products, and coatings for certain oral medications [28]. Humans are exposed to DBP on a daily basis, and daily DBP intake for the general population is $0.007-0.01 \mathrm{mg} / \mathrm{kg} /$ day [1] Detection of the urinary levels of MBP reveal that the metabolites of DBP in women of childbearing age, who are estimated to be exposed to DBP at rates that are over 200 times greater than that of a reference population, as they frequently use oral medications with DBPincorporated enteric coats [29]. In addition, in some severe cases, DBP metabolites are often found to be nearly 600 times higher than they are in the normal population $(10,025 \mu \mathrm{g} / \mathrm{g}$ creatinine vs $17 \mu \mathrm{g} / \mathrm{g}$ creatinine); these patients often require enteric-coated drugs or blood transfusions [30-33]. Furthermore, during the developmental window of foetal mice, the reproductive toxicity 
of the highest dose of DBP exposure in other studies was mostly $500 \mathrm{mg} / \mathrm{kg} /$ day $[19,34,35]$. Therefore, we established $500 \mathrm{mg} / \mathrm{kg} /$ day as the highest dose in the in vivo experiments. A previous study showed that 8 mM MBP could inhibit HCG-induced testosterone and insulin-like peptide 3 secretion in cultured testicular interstitial cells in vitro [36]. It was concluded that the in vitro cultured cells are probably insensitive to MBP [36]. Moreover, based on the data regarding the effect of $\mathrm{MBP}$ on cell viability in our previous study, the $\mathrm{EC}_{50}$ of MBP was determined to be $16.21 \mathrm{mM}$ [21]. Therefore, in this study, the highest concentration of MBP in vitro was set at $10 \mathrm{mM}$.

The pharmacokinetics of DBP have been investigated in rats [37]. DBP levels in fecal excretion was found to be low, and more than $90 \%$ of the dose was excreted via metabolites in the urine within $48 \mathrm{~h}$ following either intravenous or oral administration [37, 38]. Most DBP is metabolized to MBP by intestinal hydrolases in the small intestine, and then almost all MBP enters the bloodstream $[37,39]$. DBP can directly penetrate the bloodtestis barrier [40]. Clewell and his colleagues found that peak MBP concentrations in foetal testes were 72 and $152 \mu \mathrm{M}$ in the 100 and $500 \mathrm{mg} / \mathrm{kg} /$ day DBP exposure groups, respectively [41].

In the present study, we confirmed that prenatal exposure to $50 \mathrm{mg} / \mathrm{kg} /$ day DBP promoted SC proliferation. To investigate the mechanism by which DBP/MBP disrupted the growth of immature SCs, we employed TM4 cells derived from immature mouse SCs in an in vitro study. Mouse TM4 cells share many characteristics of
SCs and have been widely used as a substitute for primary SCs [42]. Consistent with the in vivo results, 0.1 $\mathrm{mM}$ MBP promoted proliferation and DNA synthesis in the TM4 cells, while apoptosis was significantly increased after exposure to $10 \mathrm{mM}$ MBP. We then aimed to investigate the molecular mechanism associated with the proliferation and apoptosis of SCs in MBP-treated $\mathrm{SCs}$ at different doses.

Apoptosis is an evolutionarily conserved mechanism for programming cell death, and it occurs in response to some physiological stimuli, cell damage or stress and is an important part of various developmental processes in metazoans [43, 44]. Previously, many investigations found that DBP exposure caused toxicity in several cell types, such as nerve cells, osteoblasts, and germ cells [45-47]. It has been confirmed that MBP exposure causes apoptosis of SCs, but the specific mechanism has not yet been demonstrated [8]. In this study, we analysed the protein levels of key components of the intrinsic pathways (Bax, Bcl-2, and Cyt c) and extrinsic pathways (FADD, caspase 8, and caspase 3) [18]. The results showed that $10 \mathrm{mM}$ MBP could activate the intrinsic pathway, whereas the extrinsic pathway was inhibited. Interestingly, the expression of FADD was increased after exposure to $0.1 \mathrm{mM}$ MBP (Additional file 1: Fig. S2a). A previous study showed that FADD played a role in regulating most of the signalosome complexes, causing it to emerge as a newly identified actor in innate immunity, inflammation, and cancer development [48]. Therefore, we speculated that FADD might be involved in other physiological processes after exposure to $\mathrm{MBP}$ at a concentration of $0.1 \mathrm{mM}$.

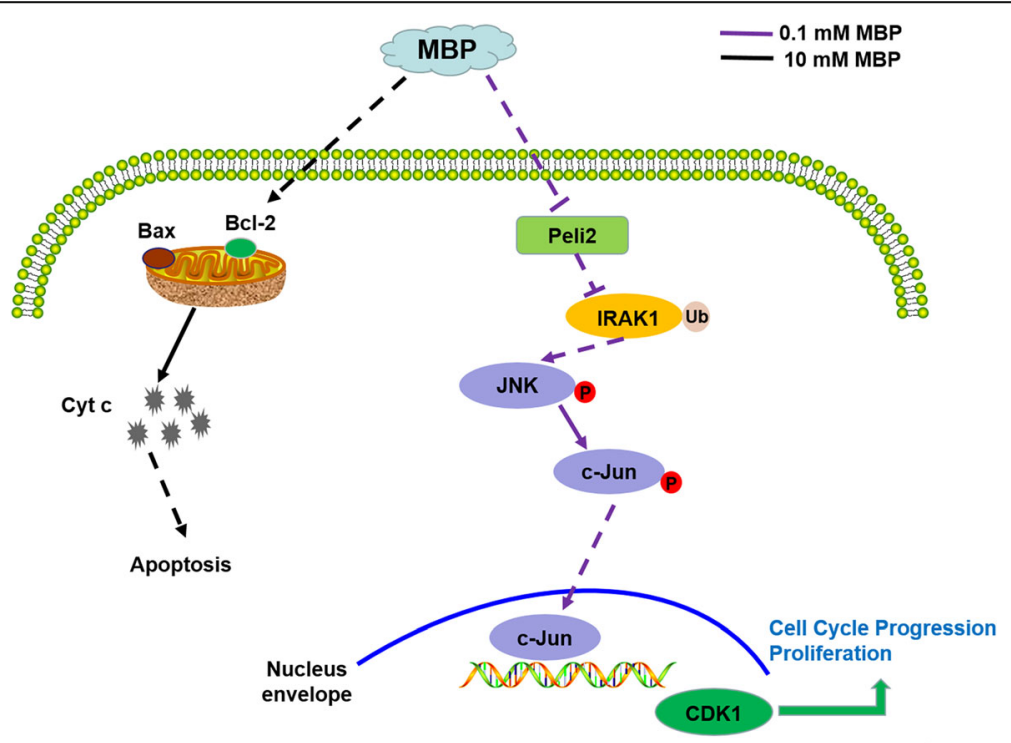

Fig. 7 Proposed model for MBP-induced abnormal cell growth of juvenile SCs. MBP at $0.1 \mathrm{mM}$ inhibits the expression of Peli2, leading to K63 ubiquitination of IRAK1, which activates the MAPKJJNK signalling pathway and promotes SC proliferation. MBP at 10 mM led to SC apoptosis through intrinsic apoptotic signalling pathways 
Pellino proteins have various regulatory roles in cell growth, for example, murine genetic models have revealed roles for Peli1 in lung carcinogenesis [49] and for Peli3 in TNF-induced cell killing [50]. However, there is a notable lack of insight into the physiological roles of Peli2. It was illustrated that polyubiquitination of both IL-1/LPS-induced K63- and K48-linked IRAK1 was decreased in Peli2-knockdown cells [27]. In our study, we found that, with decreasing Peli2 expression, the total ubiquitination level was reduced, while K63-linked IRAK1 polyubiquitination was increased after exposure to $0.1 \mathrm{mM}$ MBP. Therefore, we hypothesized that the decreasing IRAK1 ubiquitination was mainly due to K48-ubiquitination, which resulted in the degradation of IRAK1. Studies on Peli2 revealed a role for Peli2 in IL-1/ LPS-induced activation of the MAPK/JNK pathway [27, 51]. Our data also found that $0.1 \mathrm{mM}$ MBP activated IRAK1 and the downstream MAPK/JNK signalling pathway, suggesting that $0.1 \mathrm{mM} \mathrm{MBP}$ could promote immature SC growth through the Peli2/IRAK1/MAPK/ JNK pathway. Taken together, it was concluded that 0.1 $\mathrm{mM}$ MBP promoted the abnormal proliferation of SCs by inhibiting the expression of Peli2, disrupting the balance of IRAK1 ubiquitination, and activating the downstream MAPK/JNK signalling pathway.

\section{Conclusions}

In summary, we first confirmed that DBP/MBP stimulated the proliferation of SCs in vitro and in vivo at a relatively low concentration range. Then, we found that downregulated Peli2 resulted in increased K63 ubiquitination of IRAK1, which activated MAPK/JNK signalling pathways in TM4 cells treated with $0.1 \mathrm{mM}$ MBP. In addition, we showed that $10 \mathrm{mM}$ MBP caused apoptosis of TM4 cells by activating the intrinsic apoptotic pathway. A descriptive outline of this study is shown in Fig. 7.

\section{Supplementary information}

Supplementary information accompanies this paper at https://doi.org/10. 1186/s12940-020-00639-1.

Additional file $\mathbf{1}$ Table S1. Specifications of primary antibodies. Table S2. Primers used for q-PCR. Figure S1. Cytochrome $C$ (Cyt C) released was induced by MBP at $10 \mathrm{mM}$ group. Figure S2. The extrinsic apoptotic pathway do not participated in MBP-induced apoptosis of TM4 cells.

Figure S3. MBP induces the activation of MAPK JNKK-associated protein in TM4 cells.

\section{Abbreviations}

DBP: Dibutyl phthalate; MBP: Monobutyl phthalate; SCs: Sertoli cells; Peli2: Pellino 2; IRAK1: Interleukin 1 receptor-associated kinase 1

\section{Acknowledgments}

The authors are grateful to the National Natural Science Foundation of China for financial supports.

\section{Authors' contributions}

TM coordinated field research, performed the data analysis, and prepared the manuscript. Histopathological sections were analysed by JH. YZ analysed gene expression. YC and JQ contributed to the collection of animal tissue samples. JW, JD, XH participated in the research design and coordinated funding support. DL coordinated the overall project implementation. As a Principal Investigator, DL conceived and designed the entire research and experiment, seeking financial support and writing manuscripts. All authors read and approved the final manuscript.

\section{Funding}

This work was supported by National Natural Science Foundation of China (31971517, 31870492 and 31670519), Fundamental Research Funds for the Central Universities (0214-14380438) and Supported by Nanjing University Innovation and Creative Program for PhD candidate (CXCY19-49).

\section{Availability of data and materials}

All data generated during this study are included in this published article and its additional files.

\section{Ethics approval and consent to participate}

All procedures performed on animals were approved by the Animal Care and Use Committee of Nanjing University under the animal protocol number SYXK (Su) 2009-0017. The animal experiments were performed in accordance with the Guide for the Care and Use of Laboratory Animals (The Ministry of Science and Technology of China, 2006).

\section{Consent for publication}

We have obtained consents to publish this paper from all the participants of this study.

\section{Competing interests}

The authors declare no conflict of interests.

Received: 10 July 2019 Accepted: 27 July 2020

Published online: 01 August 2020

\section{References}

1. Kavlock R, Boekelheide K, Chapin R, Cunningham M, Faustman E, Foster P, Golub M, Henderson R, Hinberg I, Little R, et al. NTP Center for the Evaluation of risks to human reproduction: phthalates expert panel report on the reproductive and developmental toxicity of di (2-ethylhexyl) phthalate. Reprod Toxicol. 2002;16(5):529-653.

2. Guo Y, Zhang Z, Liu L, Li Y, Ren N, Kannan K. Occurrence and profiles of phthalates in foodstuffs from China and their implications for human exposure. J Agric Food Chem. 2012;60(27):6913-9.

3. Mahood IK, Scott HM, Brown R, Hallmark N, Walker M, Sharpe RM. In utero exposure to di(n-butyl) phthalate and testicular dysgenesis: comparison of fetal and adult end points and their dose sensitivity. Environ Health Perspect. 2007;115(Suppl 1):55-61.

4. Kleymenova E, Swanson C, Boekelheide K, Gaido KW. Exposure in utero to di(n-butyl) phthalate alters the vimentin cytoskeleton of fetal rat Sertoli cells and disrupts Sertoli cell-gonocyte contact. Biol Reprod. 2005;73(3):482-90.

5. Ma T, Yin X, Han R, Ding J, Zhang H, Han X, Li D. Effects of in utero exposure to di-n-butyl phthalate on testicular development in rat. Int J Environ Res Public Health. 2017;14(10):1284.

6. Li D, Hu Y, Shen X, Dai X, Han X. Combined effects of two environmental endocrine disruptors nonyl phenol and di-n-butyl phthalate on rat Sertoli cells in vitro. Reprod Toxicol. 2010;30(3):438-45.

7. Hu Y, Wang R, Xiang Z, Qian W, Han X, Li D. Antagonistic effects of a mixture of low-dose nonylphenol and di-n-butyl phthalate (monobutyl phthalate) on the Sertoli cells and serum reproductive hormones in prepubertal male rats in vitro and in vivo. PLoS One. 2014;9(3):e93425.

8. Hu Y, Wang R, Xiang Z, Qian W, Han X, Li D. Mixture effects of nonylphenol and di-n-butyl phthalate (monobutyl phthalate) on the tight junctions between Sertoli cells in male rats in vitro and in vivo. Exp Toxicol Pathol. 2014;66(9-10):445-54

9. Yin X, Ma T, Han R, Ding J, Zhang H, Han X, Li D. MiR-301b-3p/3584-5p enhances low-dose mono-n-butyl phthalate (MBP)-induced proliferation by targeting Rasd1 in Sertoli cells. Toxicol in Vitro. 2018;47:79-88. 
10. Mruk DD, Cheng CY. Sertoli-Sertoli and Sertoli-germ cell interactions and their significance in germ cell movement in the seminiferous epithelium during spermatogenesis. Endocr Rev. 2004;25(5):747-806.

11. Agmo A. Male rat sexual behavior. Brain Res Brain Res Protoc. 1997;1(2):203-9.

12. Jegou B. The Sertoli-germ cell communication network in mammals. Int Rev Cytol. 1993;147:25-96

13. Medvedev AE, Murphy M, Zhou H, Li X. E3 ubiquitin ligases Pellinos as regulators of pattern recognition receptor signaling and immune responses. Immunol Rev. 2015;266(1):109-22

14. Lin CC, Huoh YS, Schmitz KR, Jensen LE, Ferguson KM. Pellino proteins contain a cryptic FHA domain that mediates interaction with phosphorylated IRAK1. Structure. 2008;16(12):1806-16.

15. Moynagh PN. The roles of Pellino E3 ubiquitin ligases in immunity. Nat Rev Immunol. 2014;14(2):122-31.

16. Li G, Ying L, Wang H, Wei SS, Chen J, Chen YH, Xu WP, Jie QQ, Zhou Q, Li YG, et al. Rac1b enhances cell survival through activation of the JNK2/CJUN/Cyclin-D1 and AKT2/MCL1 pathways. Oncotarget. 2016;7(14):17970-85.

17. Wee ZN, Yatim SM, Kohlbauer VK, Feng M, Goh JY, Bao Y, Lee PL, Zhang S, Wang PP, Lim E, et al. IRAK1 is a therapeutic target that drives breast cancer metastasis and resistance to paclitaxel. Nat Commun. 2015;6:8746.

18. Qian W, Zhu J, Mao C, Liu J, Wang Y, Wang Q, Liu Y, Gao R, Xiao H, Wang J. Involvement of CaM-CaMKII-ERK in bisphenol A-induced Sertoli cell apoptosis. Toxicology. 2014;324:27-34

19. Gaido KW, Hensley JB, Liu D, Wallace DG, Borghoff S, Johnson KJ, Hall SJ, Boekelheide K. Fetal mouse phthalate exposure shows that Gonocyte multinucleation is not associated with decreased testicular testosterone. Toxicol Sci. 2007;97(2):491-503.

20. Chen Y, Zhou Y, Wang J, Wang L, Xiang Z, Li D, Han X. Microcystin-Leucine arginine causes cytotoxic effects in Sertoli cells resulting in reproductive dysfunction in male mice. Sci Rep. 2016;6:39238.

21. Hu Y, Li DM, Han XD. Analysis of combined effects of nonylphenol and Monobutyl phthalate on rat Sertoli cells applying two mathematical models. Food Chem Toxicol. 2012;50(3-4):457-63.

22. Livak KJ, Schmittgen TD. Analysis of relative gene expression data using real-time quantitative PCR and the 2(-Delta Delta C(T)) method. Methods. 2001;25(4):402-8.

23. Chen Y, Wang J, Zhang Q, Xiang Z, Li D, Han X. Microcystin-leucine arginine exhibits immunomodulatory roles in testicular cells resulting in orchitis. Environ Pollut. 2017;229:964-75.

24. Yu KY, Kwon HJ, Norman DA, Vig E, Goebl MG, Harrington MA. Cutting edge: mouse pellino-2 modulates IL-1 and lipopolysaccharide signaling. J Immunol. 2002;169(8):4075-8.

25. Schauvliege R, Janssens S, Beyaert R. Pellino proteins are more than scaffold proteins in TLR/IL-1R signalling: a role as novel RING E3-ubiquitin-ligases. FEBS Lett. 2006;580(19):4697-702.

26. Chu H, Qu X, Wang F, Chang J, Cheng R, Song X, Chen T, Zhang G. MicroRNA-206 promotes lipopolysaccharide-induced inflammation injury via regulation of IRAK1 in MRC-5 cells. Int Immunopharmacol. 2019;73:590-8.

27. Kim TW, Yu M, Zhou H, Cui W, Wang J, DiCorleto P, Fox P, Xiao H, Li X Pellino 2 is critical for toll-like receptor/interleukin-1 receptor (TLR/IL-1R)mediated post-transcriptional control. J Biol Chem. 2012;287(30):25686-95.

28. Hernandez-Diaz S, Mitchell AA, Kelley KE, Calafat AM, Hauser R. Medications as a potential source of exposure to phthalates in the U.S. population. Environ Health Perspect. 2009;117(2):185-9.

29. Hernandez-Diaz S, Su YC, Mitchell AA, Kelley KE, Calafat AM, Hauser R. Medications as a potential source of exposure to phthalates among women of childbearing age. Reprod Toxicol. 2013;37:1-5.

30. Koch HM, Christensen KL, Harth V, Lorber M, Bruning T. Di-n-butyl phthalate (DnBP) and diisobutyl phthalate (DiBP) metabolism in a human volunteer after single oral doses. Arch Toxicol. 2012;86(12):1829-39.

31. Seckin $\mathrm{E}$, Fromme H, Volkel W. Determination of total and free mono-nbutyl phthalate in human urine samples after medication of a di-n-butyl phthalate containing capsule. Toxicol Lett. 2009;188(1):33-7.

32. Rael LT, Bar-Or R, Ambruso DR, Mains CW, Slone DS, Craun ML, Bar-Or D. Phthalate esters used as plasticizers in packed red blood cell storage bags may lead to progressive toxin exposure and the release of pro-inflammatory cytokines. Oxidative Med Cell Longev. 2009;2(3):166-71.

33. Hauser R, Duty S, Godfrey-Bailey L, Calafat AM. Medications as a source of human exposure to phthalates. Environ Health Perspect. 2004;112(6):751-3.

34. Moody S, Goh H, Bielanowicz A, Rippon P, Loveland KL, Itman C. Prepubertal mouse testis growth and maturation and androgen production are acutely sensitive to di-n-butyl phthalate. Endocrinology. 2013;154(9): 3460-75.

35. Saffarini CM, Heger NE, Yamasaki H, Liu T, Hall SJ, Boekelheide K. Induction and persistence of abnormal testicular germ cells following gestational exposure to di-(n-butyl) phthalate in p53-null mice. J Androl. 2012;33(3): 505-13.

36. Pathirana IN, Kawate N, Tsuji M, Takahashi M, Hatoya S, Inaba T, Tamada H In vitro effects of estradiol-17beta, monobutyl phthalate and mono-(2ethylhexyl) phthalate on the secretion of testosterone and insulin-like peptide 3 by interstitial cells of scrotal and retained testes in dogs. Theriogenology. 2011;76(7):1227-33.

37. Chang LW, Hou ML, Tsai TH. Pharmacokinetics of dibutyl phthalate (DBP) in the rat determined by UPLC-MS/MS. Int J Mol Sci. 2013;14(1):836-49.

38. Tanaka A, Matsumoto A, Yamaha T. Biochemical studies on phthalic esters. III. Metabolism of dibutyl phthalate (DBP) in animals. Toxicology. 1978;9(1-2):109-23.

39. Rowland IR, Cottrell RC, Phillips JC. Hydrolysis of phthalate esters by the gastro-intestinal contents of the rat. Food Cosmet Toxicol. 1977;15(1):17-21.

40. Zeng Q, Wei C, Wu Y, Li K, Ding S, Yuan J, Yang X, Chen M. Approach to distribution and accumulation of dibutyl phthalate in rats by immunoassay. Food Chem Toxicol. 2013;56:18-27.

41. Clewell RA, Kremer JJ, Williams CC, Campbell JL, Sochaski MA, Andersen ME, Borghoff SJ. Kinetics of selected di-n-butyl phthalate metabolites and fetal testosterone following repeated and single administration in pregnant rats. Toxicology. 2009;255(1-2):80-90.

42. Mather JP. Establishment and characterization of two distinct mouse testicular epithelial cell lines. Biol Reprod. 1980;23(1):243-52.

43. Fuchs $Y$, Steller $H$. Programmed cell death in animal development and disease. Cell. 2011;147(4):742-58.

44. Yamaguchi Y, Miura M. Programmed cell death and Caspase functions during neural development. Curr Top Dev Biol. 2015;114:159-84.

45. Wang H, Wang J, Zhang J, Jin S, Li H. Role of PI3K/AKT/mTOR signaling pathway in DBP-induced apoptosis of testicular sertoli cells in vitro. Environ Toxicol Pharmacol. 2017;53:145-50.

46. Li XJ, Jiang L, Chen L, Chen HS, Li X. Neurotoxicity of dibutyl phthalate in brain development following perinatal exposure: a study in rats. Environ Toxicol Pharmacol. 2013:36(2):392-402.

47. Sabbieti MG, Agas D, Santoni G, Materazzi S, Menghi G, Marchetti L. Involvement of p53 in phthalate effects on mouse and rat osteoblasts. J Cell Biochem. 2009;107(2):316-27.

48. Mouasni S, Tourneur L. FADD at the crossroads between Cancer and inflammation. Trends Immunol. 2018:39(12):1036-53.

49. Jeon YK, Kim CK, Hwang KR, Park HY, Koh J, Chung DH, Lee CW, Ha GH. Pellino-1 promotes lung carcinogenesis via the stabilization of slug and snail through K63-mediated polyubiquitination. Cell Death Differ. 2017;24(3): 469-80.

50. Yang S, Wang B, Tang LS, Siednienko J, Callanan JJ, Moynagh PN. Pellino3 targets RIP1 and regulates the pro-apoptotic effects of TNF-alpha. Nat Commun. 2013:4:2583.

51. Jensen LE, Whitehead AS. Pellino2 activates the mitogen activated protein kinase pathway. FEBS Lett. 2003;545(2-3):199-202.

\section{Publisher's Note}

Springer Nature remains neutral with regard to jurisdictional claims in published maps and institutional affiliations.

Ready to submit your research? Choose BMC and benefit from:

- fast, convenient online submission

- thorough peer review by experienced researchers in your field

- rapid publication on acceptance

- support for research data, including large and complex data types

- gold Open Access which fosters wider collaboration and increased citations

- maximum visibility for your research: over $100 \mathrm{M}$ website views per year

At $\mathrm{BMC}$, research is always in progress.

Learn more biomedcentral.com/submission 